\title{
Local Bupivacaine Infiltration to Reduce Pain after Tonsillectomy: A Low Cost Approach
}

\author{
https://doi.org/10.47210/bjohns.2020.v28i3.318
}

Rakesh B S, ${ }^{1}$ Bharathi M B, ${ }^{1}$ Thanzeemunisa $U,{ }^{1}$ Kumar Shankar De, ${ }^{1}$ Nitish Aggarwal ${ }^{1}$

\section{$\underline{\text { Introduction }}$}

\section{$\underline{\text { ABSTRACT }}$}

Congenital deafness in a child is often missed. Several distraction tests have evolved over time to diagnose congenital deafness. Tonsillectomy is one of the most commonly performed surgical procedures worldwide, with the major drawback of significant post operative pain.There is no consensus regarding topical application or local infiltration of anesthetics post operatively to reduce pain. The present study was performed to evaluate the effect of bupivacaine infiltration in the tonsillar fossae after tonsillectomy.

\section{Materials and Methods}

A double-blinded clinical trial was performed on 75 patients undergoing tonsillectomy between January 2019 and January 2020. All patients underwent tonsillectomy under general anesthesia and were then randomly divided into 3 groups of 25 patients each. For Group I, a swab soaked in normal saline was applied to the tonsillar fossae for 5 minutes just before extubation. In Group II, a swab soaked in $5 \mathrm{ml}$ of $0.5 \%$ bupivacaine was placed for 5 minutes, while in Group III, $5 \mathrm{ml}$ of $0.5 \%$ bupivacaine was infiltrated in the tonsillar fossae. The intensity of pain for each group was measured in the immediate post op period, at6 hours, 24 hours and 1 week by Wong Baker Faces Pain Rating Scale.

\section{$\underline{\text { Results }}$}

There was a significant difference in the mean level of pain between groups I and III in the immediate post op period, at 6 hours and 24 hours. Although the average pain scores of group III were better than those of group II, the results were significant only in the 6 hour post op period.

\section{Conclusion}

To reduce post-tonsillectomy pain, $0.5 \%$ bupivacaine can be infiltrated into the tonsillar fossa. Keywords

Tonsillectomy;Pain;Bupivacaine;Anesthesia,Local

$\mathrm{T}$ Tonsillectomy is one of the most commonly performed procedures worldwide, with the major drawback of significant amount of post operative pain. Decreasing the pain postoperatively has multiple benefits such as shorter recovery period, faster return to regular diet, and activity, improving overall condition of the patients and bringing relief to the caregivers. ${ }^{1}$

\section{1 - Department of ENT, JJSSAHER}

\section{Corresponding author:}

Dr Rakesh B S

email: rakes_bs@yahoo.com
Although analgesic drugs are used orally or parenterally post tonsillectomy, pain remains one of the main complaints after this surgery, especially in adults, who may not have significant reduction in pain, till day 9 postoperatively in some cases. ${ }^{2}$

Decreasing post tonsillectomy pain has been the subject of intense research, with various novel methods being applied for the same. Interventions have included administration of corticosteroids, Coblator assisted tonsillectomy, systemic analgesics, local infiltration with anaesthetic agents or even low dose tramadol given at the beginning of the procedure. . $^{3,5,5,7}$

The present study was performed to evaluate the effect 


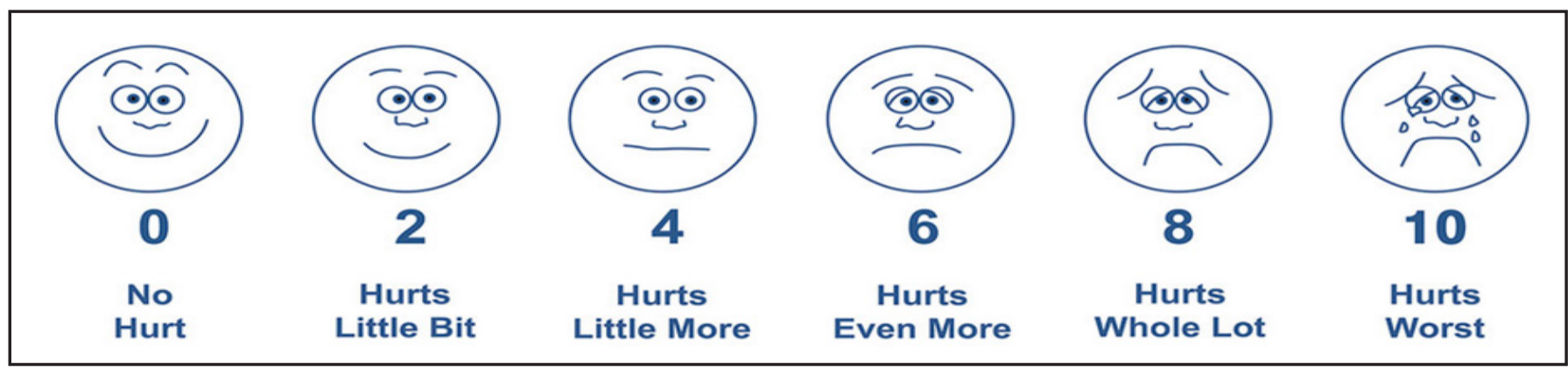

Fig. 1. Wong Baker FACES ${ }^{\circledR}$ Pain Rating Scale.

of $0.5 \%$ bupivacaine infiltration in the tonsillar fossae after tonsillectomy, just before extubation, in patients older than 9 years of age.

\section{Materials and Methods}

A double-blinded clinical trial was performed on 75 patients aged 9-25 years who had undergone tonsillectomy between January 2019 and January 2020. Patients included in the study were those who fulfilled the Paradise Criteria (at least 7 episodes of tonsilitis in the past year, at least 5 episodes in each of the previous 2 years, or at least 3 episodes in each of the previous 3 years). Any patients with signs and symptoms of active infection were excluded. Informed written consent was obtained from each patient and his/her caregivers, and routine blood investigations were done.

All patients underwent tonsillectomy by dissection and snare method by the same surgeon (author 1), under general anesthesia. Hemostasis was achieved by ligating the bleeding vesels in the tonsillar fossae. Following this, the patients were randomly divided into 3 groups.

For each person in Group I, a swabsoaked in $5 \mathrm{ml}$ of normal saline was placed in the tonsillar fossae for 5 minutes; in Group II, a swab soaked in $5 \mathrm{ml}$ of $0.5 \%$ bupivacaine was placed ineach tonsillar fossa for 5 minutes, and in Group III, $5 \mathrm{ml}$ of $0.5 \%$ bupivacaine solution was infiltrated into each tonsillar fossa post operatively. Group allocation was randomly done for each patient. All patients were given oral ibuprofen in weight-adjusted doses $(10 \mathrm{mg} / \mathrm{kg} /$ dose every 8 hours) post operatively.

The intensity of post-tonsillectomy pain was recorded in the immediate post operative period, at 6 hours, one day and one week after surgery by Wong Baker Faces Pain Rating Scale. This scale (Fig. 1) is a self-assessment tool that must be understood by the patient so that they are able to choose the rating that best illustrates the physical pain they are experiencing. It consists of a face chart with a pain rating below each face and the patient has to record his or her pain score from zero (no pain) to ten (severe pain).

Data was analyzed by one-way ANOVA with $95 \%$ confidence interval.

\section{Results}

In the immediate post op period, the mean intensity of pain in Group I was 5.52, with maximum patients recording a pain reading of 6 . The mean intensity of pain in Group II was 3.76 with most patients recording a pain score of 4, while the mean in Group III was 2.96, with most patients recording a score of 2 . Difference in pain scores among groups I and III was statistically significant $(p<0.05)$. Though group III showed overall lesser pain scores than group II, the difference was not statistically significant (Fig. 2).

When the pain scores were recorded 6 hours post op, Group I again had an overall higher mean pain score of 4.24, with most patients recording 6 again. In Group II, the patients had a mean of 3.2 with maximum patients having a score of 2 and Group III had a mean of 1.76 , with the majority of patients showing a score of 2 . The differences were statistically significant $(p<0.05)$. The difference between Groups II and III at 6 hours post-op was alsostatistically significant, with Group III showing 


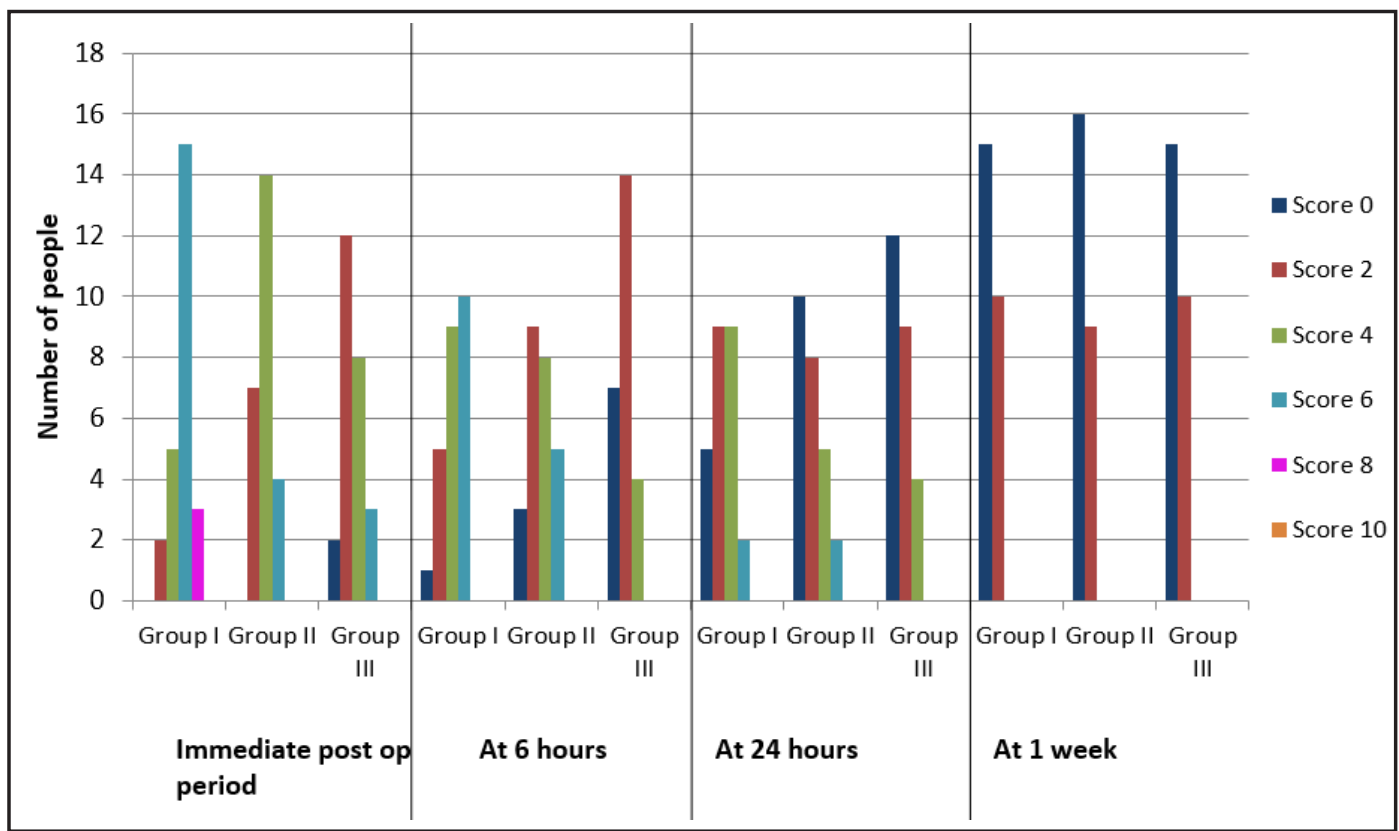

Fig. 2. The pain scores for patients in Group I, II and III in the immediate post op period, at 6 hours, at 24 hours and at 1 week post operatively

a drastic improvement in pain (Fig. 2).

24 hours after surgery, the pain scores of Group I dropped to a mean of 2.64 , while the average scores of Groups II and III were 1.92 and 1.36 respectively. When compared the results of groups I and III showed a statistically significant difference, while the difference between Groups II and III was not statistically significant. The overall pain scores in Group III were nevertheless lesser than Group II (Fig. 2).

1 week after surgery Group I showed an average pain score of 0.8 , Group II showed 0.72 and Group III showed 0.8 . There was no statistically significant difference between the groups (Fig. 2).

The results are represented graphically below, with Figure 2 showing pain scores for Groups I, II and III in the immediate post op period, 6 hours after surgery, 24 hours after surgery, and 1 week after surgery.

\section{Discussion}

Tonsillectomy is one of the most commonly performed procedures worldwide, with the major drawback being significant post-operative pain. Alleviation of post- operative pain has multiple benefits such as shorter recovery period, faster return to regular diet and activity, improvement of overall condition of the patients and relief for the caregivers. ${ }^{1}$

Bupivacaine is an amide linked local anaesthetic that blocks nerve conduction by decreasing the entry of sodium $(\mathrm{Na}+)$ ions during upstroke of action potential. It interacts with a receptor situated within the voltage sensitive $\mathrm{Na}+$ channel and raises the threshold of channel opening. $\mathrm{Na}+$ permeability fails to increase in response to a stimulus and the impulse conduction is interrupted when the $\mathrm{Na}+$ channels are blocked. ${ }^{8}$

The dose of bupivacaine for peripheral block is 5-20 $\mathrm{ml}$ of $0.25 \%$ solution; the effect lasts $4-24$ hours (mean: $8 \mathrm{~h}$ ), but it may last up to 1 week after surgery because of pre-emptive analgesia mechanism. ${ }^{9}$

Hung et al. demonstrated in a study on 99 patients aged between 3 and 16 years that bupivacaine-soaked swabs tightly packed in the tonsillar fossae after tonsillectomy resulted in patients starting to drink and eat earlier than the control group. The pain scores at $1(\mathrm{p}<0.001), 3$ $(\mathrm{p}<0.001)$ and $6(\mathrm{p}<0.001)$ hours post-operation were also found to be lower in the bupivacaine group than the control group. ${ }^{10}$ 


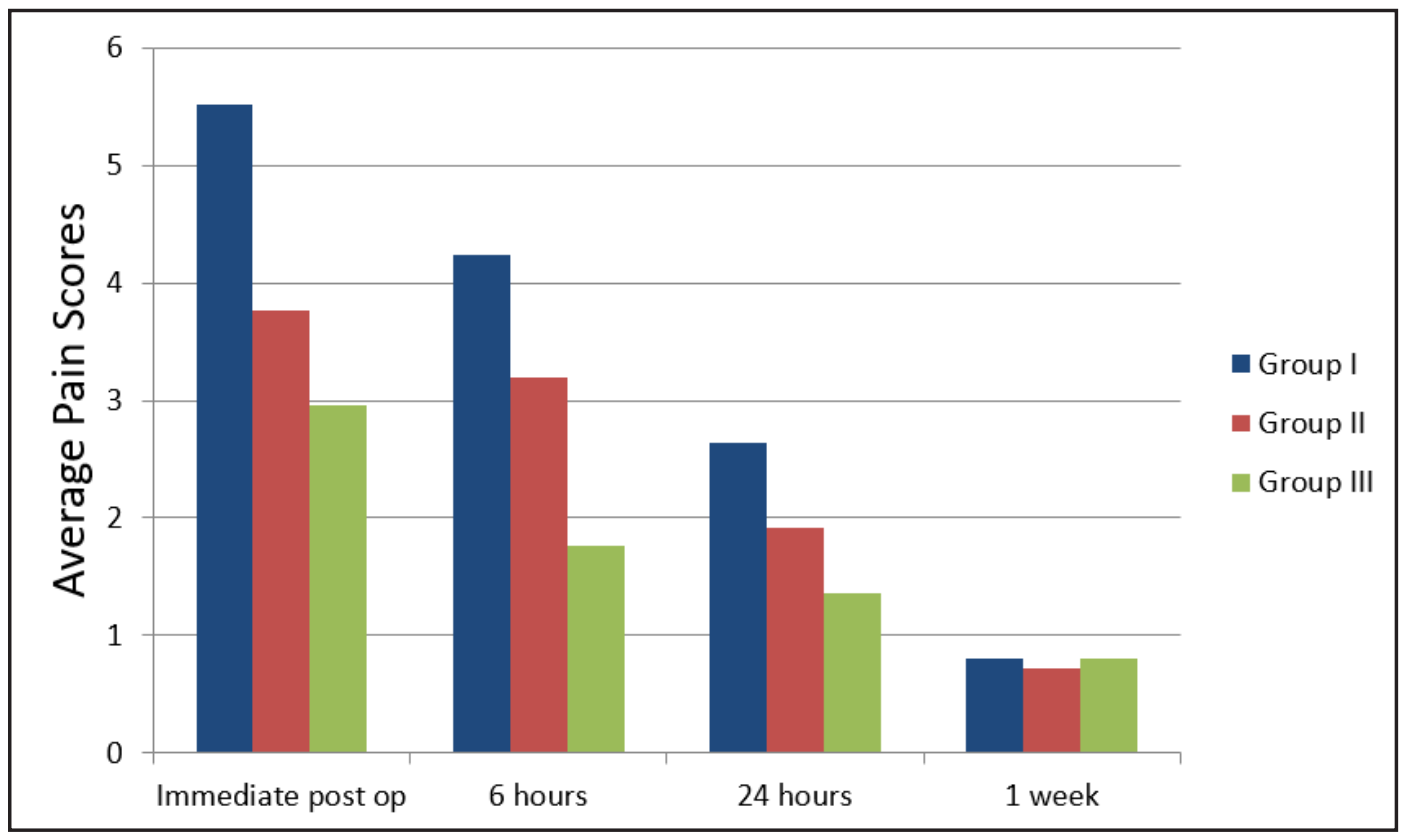

Fig. 3. A comparison of average pain scores of all 3 groups in the immediate post op period, at 6 hours, at 24 hours and at 1 week

Studies by Johansen et al., ${ }^{11}$ Jebeles et al. ${ }^{12}$ and Alvarez et al. ${ }^{13}$ have demonstrated that pre incision infiltration of bupivacaine into the tonsillar fossae have a significant impact on pain in the post operative period, especially in the first 2-3 days.

Other studies by Wong et al., ${ }^{14}$ Kountakis et al. ${ }^{15}$ have also demonstrated that infiltration of bupivacaine in the tonsillar fossa after tonsillectomy also decreases postoperative pain.

Molliex et al. in their study of 68 patients found that infiltration of tonsilswith bupivacaine produces mild decrease in pain after tonsillectomy; however, effect of bupivacaine infiltration is the same whether it is performed before or after surgery. ${ }^{6}$

Other studies have demonstrated that infiltration of bupivacaine provides little or no post operative relief of pain in patients. ${ }^{16,17,18,19}$

Although analgesics such as tramadol decrease post operative pain, data from short term studies show tramadol causes nausea, tiredness, vomiting, sweating, drowsiness and postural hypotension. Although predominantly mild in nature, the most commonly reported side-effects were headache, nausea, vomiting, dizziness and somnolence. These were significantly higher after dental surgery, possibly as a result of acute dosing of awake patients and rapid patient mobilization. Hence its use is not advocated after this surgery. ${ }^{20}$

All of our patients were also given oral ibuprofen in weight-adjusted doses $(10 \mathrm{mg} / \mathrm{kg} /$ dose every 8 hours $)$ postoperatively as this is the only other intervention for pain recommended by American Academy of Otolaryngology-Head and Neck Surgery in their 2019 clinical practice guideline update for tonsillectomy. ${ }^{21}$

Electrocautery was avoided in our study since it has been generally accepted via multiple studies that cold steel results in lesser post operative pain and decreased recovery period when compared to electrocautery. ${ }^{22,23}$

Coblation assisted tonsillectomy, although a superior method with lesser post operative pain and hemorrhage, ${ }^{24}$ is not a viable option for all centres in India, due to the lack of availability of this technology, and because it is significantly more expensive when compared to dissection and snare method. It is also associated with a longer learning curve. ${ }^{25} \mathrm{JP}$ Windfuhr ${ }^{26}$ in a review of literature concluded that calculation of cost-effectiveness of Coblation tonsillectomy is currently not possible. Similarly, harmonic scalpel assisted tonsillectomy also shares the same problems of being non-cost effective, ${ }^{27}$ 
and with most studies concluding that it may ultimately have little to no effect on post operative pain scores of patients when compared to other methods such as cold steel or electrocautery. ${ }^{28,}{ }^{29}$ Bupivacaine, on the other hand, is readily available in the operating theatre, at minimal cost.

Although local infiltration of Bupivacaine is generally considered safe, Bean-Lijewski in a retrospective study reported two cases of upper airway obstruction following pre-tonsillar injection of bupivacaine. But the author concedes that retrospective analyses are flawed due to their inability to control clinical variables. Wide variations in anesthetic techniques, concentration, and amount of local anesthetic and patients' age may occur. In addition, selection bias can result in disparity between groups, which can lead to erroneous conclusions. ${ }^{30}$

This study showed that there was a significant difference in the mean level of post-tonsillectomy pain between groups I and III in the immediate post op period, at 6 hours and at 24 hours. Although the average pain scores of group III were better than even group II, the results were significant only in the 6 hour post op period.(Fig. 3)

\section{References}

1. Ohlms LA. Injection of local anesthetic in tonsillectomy. Archives of Otolaryngology-Head \& Neck Surgery 2001; 127(10):1276-8

2. Lavy JA. Post-tonsillectomy pain: the difference between younger and older patients. International Journal of Pediatric Otorhinolaryngology 1997; 42(1):11-5

3. Afman CE, Welge JA, Steward DL. Steroids for posttonsillectomy pain reduction: meta-analysis of randomized controlled trials. Otolaryngology-Head and Neck Surgery 2006;134(2):181-6

4. Businco LD, Tirelli GC. Paediatric tonsillectomy: radiofrequency-based plasma dissection compared to cold dissection with sutures. Acta Otorhinolaryngologica Italica 2008; 28(2):67

5. Özköse Z, Akçabay M, Kemaloğlu YK, Sezenler S. Relief of posttonsillectomy pain with low-dose tramadol given at induction of anesthesia in children. International Journal of Pediatric Otorhinolaryngology. 2000; 53(3):207-14

6. Molliex S, Haond P, Baylot D, Prades JM, Navez M, Elkhoury $\mathrm{Z}$, Auboyer C. Effect of pre-vs postoperative tonsillar infiltration with local anesthetics on postoperative pain after tonsillectomy.
Acta Anaesthesiologica Scandinavica 1996; 40(10):1210-5

7. Jebeles JA, Reilly JS, Gutierrez JF, Bradley Jr EL, Kissin I. The effect of pre-incisional infiltration of tonsils with bupivacaine on the pain following tonsillectomy under general anesthesia. Pain 1991; 47(3):305-8

8. Tripathi KD. Essentials of medical pharmacology. JP Medical Ltd; 2013

9. Safavi NS, Sharifian H, Fath AM, Fatahi BA. Effect of local bupivacaine infiltration on post-tonsillectomy pain. TANAFFOS 2006; 5(1)(17):45-9

10. Hung T, Moore-Gillon V, Hern J, Hinton A, Patel N. Topical bupivacaine in paediatric day-case tonsillectomy: a prospective randomized controlled trial. The Journal of Laryngology and Otology 2002;116(1):33

11. Johansen M, Harbo G, Ilium P. Preincisional infiltration with bupivacaine in tonsillectomy. Archives of OtolaryngologyHead \& Neck Surgery 1996;122(3):261-3

12. Jebeles JA, Reilly JS, Gutierrez JF, Bradley Jr EL, Kissin I. The effect of pre-incisional infiltration of tonsils with bupivacaine on the pain following tonsillectomy under general anesthesia. Pain 1991; 47(3):305-8

13. García A, MTLG. Intraoperative infiltration of $0.5 \%$ bupivacaine in pediatric tonsillectomy. Acta Otorrinolaringologica Espanola 1997; 48(4):287-90

14. Wong AK, Bissonnette B, Braude BM, Macdonald RM, St-Louis PJ, Fear DW. Post-tonsillectomy infiltration with bupivacaine reduces immediate postoperative pain in children. Canadian Journal of Anaesthesia 1995; 42(9):770-4

15. Kountakis SE. Effectiveness of perioperative bupivacaine infiltration in tonsillectomy patients. American Journal of Otolaryngology 2002; 23(2):76-80

16. Schoem SR, Watkins GL, Kuhn JJ, Alburger JF, Kim KZ, Thompson DH. Control of early postoperative pain with bupivacaine in adult local tonsillectomy. Archives of Otolaryngology-Head \& Neck Surgery 1993; 119(3):292-3

17. Stuart JC, MacGregor FB, Cairns CS, Chandrachud HR. Peritonsillar infiltration with bupivacaine for paediatric tonsillectomy. Anaesthesia and Intensive Care 1994; 22(6):67982

18. Schoem SR, Watkins GL, Kuhn JJ, Thompson DH. Control of early postoperative pain with bupivacaine in pediatric tonsillectomy. Ear, Nose \& Throat Journal 1993; 72(8):560-3

19. Nordahl SH, Albrektsen G, Guttormsen AB, Pedersen IL, Breidablikk HJ. Effect of bupivacaine on pain after tonsillectomy: a randomized clinical trial. Acta Otolaryngologica 1999; 119(3):369-76

20. Shipton EA. Tramadol-present and future. Anaesthesia and Intensive Care 2000; 28(4):363-74

21. Mitchell RB, Archer SM, Ishman SL, Rosenfeld RM, Coles S, Finestone SA, Friedman NR, Giordano T, Hildrew DM, Kim TW, Lloyd RM. Clinical practice guideline: tonsillectomy in 
children (update). Otolaryngology-Head and Neck Surgery 2019; 160(1_suppl):S1-42

22. Nunez DA, Provan J, Crawford M. Postoperative tonsillectomy pain in pediatric patients: electrocautery (hot) vs cold dissection and snare tonsillectomy - a randomized trial. Archives of Otolaryngology-Head \& Neck Surgery 2000; 126(7):837-41

23. Leinbach RF, Markwell SJ, Colliver JA, Lin SY. Hot versus cold tonsillectomy: a systematic review of the literature. Otolaryngology_-Head and Neck Surgery 2003; 129(4):360-4

24. Mösges R, Hellmich M, Allekotte S, Albrecht K, Böhm M. Hemorrhage rate after coblation tonsillectomy: a metaanalysis of published trials. European Archives of Oto-RhinoLaryngology 2011; 268(6):807-16

25. Carney AS, Harris PK, MacFarlane PL, Nasser S, Esterman A. The coblation tonsillectomy learning curve. OtolaryngologyHead and Neck Surgery 2008; 138(2):149-52
26. Windfuhr JP. Studienzur Coblation-Tonsillektomie. HNO 2007; 55(5):337-48

27. Karimi E, Safaee A, Bastaninejad S, Dabiran S, Masoumi E, Salehi FM. A Comparison between Cold Dissection Tonsillectomy and Harmonic Scalpel Tonsillectomy. Iranian Journal of Otorhinolaryngology 2017; 29(95):313

28. Yi Wong DJ, Paddle P. Harmonic scalpel versus other techniques for tonsillectomy: a systematic review and metaanalysis. Australian Journal of Otolaryngology. 2019; 23;2

29. Arbin L, Enlund M, Knutsson J. Post-tonsillectomy pain after using bipolar diathermy scissors or the harmonic scalpel: a randomised blinded study. European Archives of Oto-RhinoLaryngology 2017; 274(5):2281-5

30. Bean-Lijewski JD. Glossopharyngeal nerve block for pain relief after pediatric tonsillectomy: retrospective analysis and two cases of life-threatening upper airway obstruction from an interrupted trial. Anesthesia \& Analgesia 1997; 84(6):1232-8. 